FISCHER, Marta Luciane; PALODETO, Maria Fernanda Turbay; SANTOS, Erica Costa dos. Uso de animais como zooterápicos: uma questão bioética. História, Ciências, Saúde - Manguinhos, Rio de Janeiro, v.25, n.1, jan.-mar. 2018, p.217-243.

\title{
Uso de animais como zooterápicos: uma questão bioética
}

\section{The use of animal-assisted therapy: a bioethical question}

\author{
Marta Luciane Fischer \\ Professora, Escola de Ciências da Vida (ECV)/Pontifícia Universidade \\ Católica do Paraná (PUC-PR). \\ Curitiba - PR - Brasil \\ marta.fischer@outlook.com
}

\section{Maria Fernanda Turbay Palodeto}

Mestranda, Programa de Pós-graduação em Bioética/ECV/PUC-PR. Curitiba - PR - Brasil

maria.palodeto@pucpr.br

\author{
Erica Costa dos Santos \\ Graduanda, curso de Farmácia/ECV/PUC-PR. \\ Curitiba - PR - Brasil \\ ericacostadossantos@gmail.com
}

Recebido para publicação em 09.08.2016.

Aprovado para publicação em 08.03.2017.

http://dx.doi.org/10.1590/S0104-59702018000100013

\section{Resumo}

Aborda questões éticas no uso de animais como zooterápicos, que, embora documentado há séculos para múltiplas culturas e resistente ao processo de desenvolvimento urbano e tecnológico, congrega uma pluralidade de agentes morais e vulneráveis, constituindo um dilema cuja solução consensual e justa demanda a intervenção de novas ferramentas, como a bioética ambiental. Analisando textos científicos, sistematiza os argumentos e valores intrínsecos às decisões de como e quando utilizar animais como recursos médicos. Pelo método bioético, reflete sobre soluções condicionadas à comunicação muldimensional entre os atores constituintes dos três pilares da sustentabilidade - ambiente, sociedade e economia - envolvidos nessa questão ética global, focando na conservação e na produção sustentável.

Palavras-chave: bioética ambiental; ética animal; etnofarmacologia; zooterapia.

Abstract

This paper addresses ethical questions concerning animal-assisted therapy (zootherapy). While it has been documented for centuries in several cultures and is resistant to urban and technological developments, it combines multiple moral and vulnerable agents, constituting $a$ dilemma whose fair and consensual solution calls for new perspectives, like environmental bioethics. Through analyses of scientific texts, the arguments and values intrinsic to decisions about how and when to use animals as medical resources are systematized. Using bioethics as a method, reflections are offered about the potential solutions dependent on the multidimensional communication between the players from the three pillars of sustainability - environment, society, and economy - involved in this global ethical question, focusing on conservation and sustainable production.

Keywords: environmental bioethics; animal ethics; ethnopharmacology; zootherapy. 
A relação entre os humanos e a natureza, intrinsecamente genuína e simbiótica, transpôs-se em domínio alicerçada no atributo da razão, que outorgou ao homem o direito e o dever de domesticar plantas e animais (Moura, Marques, 2008). A utilização de elementos biológicos alheios ao próprio corpo para a manutenção do metabolismo é a fundamentação vital de seres heterotróficos. Contudo, processos evolutivos possibilitaram a seleção de determinados elementos também para restauração de processos biológicos comprometedores da integridade do organismo. O uso de vegetais e minerais com potencial medicinal é conhecido em animais como primatas, aves, lobos, elefantes, rinocerontes e roedores, visando à ação antimicrobiana, estimulante, laxante, antiparasitária, antibiótica, controladora hormonal e como antídoto contra toxinas (Huffman, 1997; Hutchings et al., 2003). As plantas em geral são indigestas, com baixo potencial nutritivo, que trazem benefícios medicinais e cuja eficácia foi apropriada pelos humanos e perpetuada culturalmente (Huffman, 1997, 2003).

A Organização Mundial da Saúde (OMS) estima que cerca de $80 \%$ da população mundial utiliza a medicina popular ou tradicional. Logo, atesta sua relevância e estimula pesquisas com abordagens etnográficas, médicas, farmacológicas e ecológicas. As pesquisas fundamentadas no conhecimento popular buscam integrar tais conhecimentos ao meio científico, gerando hipóteses testáveis e resultados, muitas vezes positivos, na obtenção de novas terapias e medicamentos (Moura, Marques, 2008; Alves, Dias, 2010).

O uso medicinal dos animais vem sendo investigado por meio de pesquisas etnozoológicas, as quais interligam elementos das ciências naturais e sociais, para compreensão da relação entre homens e animais em populações tradicionais, rurais ou urbanas, e das representações dos animais no contexto histórico, econômico, sociológico, antropológico e ambiental (Alves, Souto, 2015). Alves (2012) revisou as principais interações humanos/fauna e suas repercussões na conservação, destacando a codependência, nem sempre harmoniosa, que extrapola o cunho utilitarista, uma vez que também envolve arte, religião, música e literatura. A amplitude do impacto varia entre as culturas e de acordo com o grau de sustentabilidade da exploração. Logo, segundo o autor, o grau do impacto depende do nível de conhecimento cultural, econômico, social e tradicional, sendo a apropriação desse saber pela etnozoologia potencial subsídio para elaborações de planos de manejo, uma vez que promove um canal de comunicação entre cientistas e gestores. Alves e Souto (2011) abordaram especificamente a etnozoologia brasileira, que, balizada por uma rica diversidade cultural e faunística, tem se pronunciado na última década, caracterizandose por expressões regionais. Contudo ainda se limita a listas de espécies, muitas vezes incorretas ou incompletas. Esses autores compartilham da visão de Lyra-Neves et al. (2015) segundo a qual os estudos etnozoológicos demandam aprimoramento e incorporação de delineamento metodológico fundamentados em questionamentos e hipóteses testáveis por meio de instrumentos estatísticos. Como exemplo há os estudos de Ferreira et al. (2016), que focaram a zooterapia na conservação avaliando a possibilidade de substituição do uso de animais selvagens por domésticos.

Os medicamentos bioterápicos são preparados a partir da farmacotécnica homeopática, utilizando-se de produtos biológicos tais como: secreções, excreções, tecidos e órgãos, administrados em quadros doentios sintomáticos, infecciosos de etiologia conhecida, 
hipersensibilidade, quadros clínicos fomentados por agentes tóxicos ou substâncias biológicas. Embora a obtenção de medicamentos por meio da extração de princípios ativos de vegetais seja mais popular, correspondendo a $11 \%$ dos fármacos essenciais, o uso de animais para fins medicinais, denominado zooterapia ou elemento zooterapêutico, possui representação de 8,7\% (Alves, Rosa, 2005; Moura, Marques, 2008). Contudo, a zooterapia diretamente ligada à etnofarmacologia demanda maior compreensão dos recursos naturais e sua relação com os humanos, a fim de superar a pouca atenção dispensada à significância histórica, antropológica, sociológica, cultural, farmacológica, econômica e ecológica dessa prática (Marques, 1997; Alves, Rosa, 2005; Alves et al., 2007). Dessa forma, instauram-se possibilidades de alternativas terapêuticas, muitas vezes mais condizentes com a situação socioeconômica e cultural do paciente. Torna-se também possível a descoberta de novas drogas, até mesmo mais eficazes, bem como a substituição de medicamentos alopáticos disponibilizados pela indústria farmacêutica (Marques, 1997; Alves, Dias, 2010; Alves, Alves, 2011).

O cuidado com a saúde humana é apoiado na ética utilitarista antropocêntrica e em princípios como a benevolência, o cuidado e a precaução (Boff, 2003). Contudo, embora o desenvolvimento tecnológico da humanidade tenha se direcionado para o aprimoramento de métodos de diagnósticos, medicamentos e terapias, os quais propiciaram a duplicação da expectativa de vida em cinquenta décadas (Adami, Chemin, França, 2014), é reconhecido que existem questões éticas no uso de medicamentos que devem ser debatidas, tais como: a automedicação, a diminuição do efeito do medicamento e a necessidade constante de novos medicamentos. Aspectos éticos relacionados ao mercado que se apropria das vulnerabilidades para obter lucros demandam especial atenção. Ressalta-se que, além de muitos medicamentos resultarem em efeitos colaterais, o processo vigente de produção demanda testes em animais, ou seja, a utilização de milhares de vidas ao longo do processo, somando-se aos potenciais impactos ambientais decorrentes da produção e da utilização de fármacos (Adami, Chemin, França, 2014).

Diversos questionamentos relacionados à produção e ao consumo de medicamentos alopáticos incentiva o uso de produtos naturais provenientes tanto de plantas quanto de animais. Porém, salvo os benefícios secularmente atestados, é possível identificar impactos sociais, culturais e ambientais que requerem um diálogo em prol da prevenção e remediação desses problemas. Justifica-se a abordagem bioética no uso de animais como zooterapêuticos diante de diferentes valores ambientais, culturais, éticos e sociais envolvidos nas decisões de inúmeros atores, constituídos por agentes e pacientes morais, ${ }^{1}$ uma vez que a sociedade é dotada de uma expressão cultural que resiste à pósmodernidade e, todavia, busca no natural a essência da saúde. Por outro lado, tem-se o comércio que se apropria dessa demanda maximizada pela globalização, gerando dependência e competitividade. Assim, a questão que guiou o presente estudo foi: quais são os argumentos dos atores em defesa e contrários ao uso de animais como recurso medicinal? Para responder a essa questão foram estabelecidas as seguintes hipóteses: (a) a prática tradicional da zooterapia, mesmo aparentemente distante da realidade urbana contemporânea, constitui uma questão ética atual, complexa, plural e global; (b) os setores sociais representantes da natureza, sociedade e economia podem ser inseridos no papel de 
agentes ou pacientes morais dependendo do teor de suas argumentações, com potencial de gerar vulnerabilidades; (c) é possível aplicar os enunciados da bioética ambiental na questão ética envolvida nos zooterápicos devido a sua essência multidisciplinar e à inabilidade dos códigos morais e legais em alcançar uma solução isoladamente. Essas informações poderão subsidiar a reflexão bioética na utilização dos animais como zooterápicos por meio da identificação dos agentes e pacientes morais, seus argumentos e valores nas tomadas de decisões que geram vulnerabilidades, propondo um meio de equalizar essa questão de maneira justa para todos os atores.

\section{Métodos}

A reflexão sobre a questão ética envolvida no uso de animais como zooterápicos se deu por meio da aplicação do método de análise de bioética ambiental utilizado por Fischer et al. (2014, 2016b) no estudo de questões ambientais plurais, globais e complexas envolvidas no ecoturismo e na crise hídrica. O método visa à identificação dos agentes e pacientes morais, seus argumentos e vulnerabilidades acessados por meio do levantamento dos posicionamentos dos atores envolvidos em uma problemática, da justificativa de suas decisões e do impacto das mesmas. Para tal, se procedeu a uma análise bibliográfica quantitativa e qualitativa.

A análise quantitativa visou caracterizar as referências acadêmicas a respeito da forma de utilização de animais como zooterápicos, obtidas por meio de uma amostra das informações veiculadas em textos científicos, a fim de demonstrar a abrangência da prática, sem o intuito de esgotar a congregação de todo conhecimento disponível. Elas foram recuperadas pelo motor de busca do portal da Capes utilizando-se como palavras-chave: "zooterápico", "animais medicinais" e "etnozoologia", esta última condicionada ao termo "medicina", todos em português e inglês. A busca resultou em 245 textos dos quais foram excluídos os repetidos, os inacessíveis em versão completa e aqueles de conteúdo teórico sem lista de espécies, restando 51 artigos científicos cujos dados taxonômicos, partes do corpo utilizadas e finalidades medicinais foram transcritos para planilhas eletrônicas e agrupados segundo discrepâncias e semelhanças, utilizando-se a técnica semântica de análise de conteúdo de Bardin (1982) e, então, reagrupados para quantificação. Para a caracterização do uso de animais na estética foram pesquisados textos de divulgação popular no motor de busca google.com, utilizado sem login, com os termos "animal e cosméticos", em português e inglês, sendo os resultados categorizados segundo a metodologia utilizada para medicamentos. A amostra foi definida a partir da saturação do termo atestada pela repetição do mesmo conteúdo.

Com a finalidade de complementar a caracterização da conduta popular a respeito do uso de animais com finalidade medicamentosa, foi acessada a informação de um público urbano, predominantemente do Sul do Brasil e usuário da internet. Para tal, foram veiculadas digitalmente pelo sistema Qualtrics de novembro de 2015 a fevereiro de 2016 as questões: "Você já consumiu algum chá ou remédio caseiro feito de plantas ou animais?" e "Considerando os animais invertebrados; você conhece algum animal ou produto de 
animais que pode ser utilizado como medicamento ou cosmético? Caso afirmativo, dizer qual". Essas questões compõem um questionário aprovado pelo Conselho de Ética e Pesquisa (CEP) da PUC-PR (n.902.123). A enquete foi divulgada por meio da network dos autores e em grupos de redes sociais associados a segmentos das áreas de biologia, farmácia, ativismo, feminina, fitness e de utilidade pública.

A análise documental qualitativa visou à identificação dos argumentos dos atores representantes da natureza, sociedade e economia. Os dados foram levantados por meio da análise exploratória do conteúdo de textos científicos e de legislação referentes à temática, analisados conjuntamente com o resultado quantitativo.

Os dados tabelados foram avaliados por três juízes das áreas de farmácia, biologia e bioética. A homogeneidade das amostras foi testada pelo teste de aderência não paramétrico goodness of fit, tendo como hipótese nula a ocorrência das categorias em proporções similares em um índice de confiança de 95\%.

\section{Caracterização dos atores representantes da natureza como pacientes morais no uso de zooterápicos}

A inserção dos atores representantes da natureza como pacientes morais presume que eles não têm poder de decisão sobre ser ou não utilizados como recurso medicinal. No entanto, lhes é possível assumir o papel de agentes ao ser tutelados pelo Estado, que delega a seu favor por meio de legislação, regulamentação e fiscalização (Brasil, 12 fev. 1998).

A caracterização documental da utilização de animais como zooterápicos se deu a partir da consulta de 51 artigos científicos, sendo 56\% de origem do Brasil, com predomínio da região Nordeste (63\%) quando comparado com Norte (28\%), Centro-Oeste (7\%) e Sul (2\%). Os demais registros foram relativos a abordagens mundiais (36\%) ou especificamente do México, Argentina, Tanzânia, Espanha, Coreia, Índia e Indonésia. Das 2.260 citações analisadas, os invertebrados terrestres (16\%), répteis (16\%), aves (16\%) e mamíferos $(29,5 \%)$ foram significativamente mais referidos do que invertebrados marinhos $(4,2 \%)$, anfíbios $(2,7 \%)$ e peixes $(15 \%)\left(G_{\text {test }(6)}=-1,7 \mathrm{E} 2 ; \mathrm{P}<0,0001\right)$, sendo catalogadas 1.420 espécies, com maior representatividade de invertebrados terrestres $(17 \%)$, peixes $(18,3 \%)$, aves $(17,6 \%)$ e mamíferos $(24,4 \%)\left(G_{\text {test }(9)}=-, 5 \mathrm{E} 2 ; \mathrm{P}<0,0001\right)$ (Tabela 1$)$. A média de citações por espécie foi de 1,9 9 2,3 (2.260; i.v.=1-29), sendo que $66 \%$ das espécies foram referidas apenas uma vez. Das que receberam mais de dez citações, $20 \%$ das fontes analisadas, destacaram-se: abelha-europeia e jandaia, barata, cavalo-marinho, peixe-elétrico, camaleão, cascavel, jiboia, teiú, jaboti, jacaré-de-papo-amarelo, urubu, porco-espinho, capivara, paca, peixe-boi, veado-mateiro, galinha, carneiro, bode, boi, cachorro, porco, ema, pato, pavão e pombo. Das 1.172 espécies presentes na lista brasileira de ameaçadas de 2014 (Brasil, 17 dez. 2014), apenas 4,9\% estiveram presentes no levantamento realizado, sendo predominantemente mamíferos $(60 \%, \mathrm{~N}=17)$, representados pelo tamanduá-bandeira, anta, cervo-do-pantanal, queixada, peixe-boi da Amazônia e marinho, boto-cinza, boto-cor-de-rosa, bugio, macacoaranha-peruano, macaco-barrigudo, puma, onça-pintada, leopardo, cachorro-vinagre, mocó e veado-campeiro. 
Tabela 1: Frequência relativa dos grupos taxonômicos de animais citados na utilização como zooterápicos

\begin{tabular}{|c|c|c|c|c|c|}
\hline & $\begin{array}{l}\text { Grupos zoológicos relatados } \\
\text { Média de citações por táxon: } 1,9 \pm 2,3(\mathrm{~N}=2260 ; \text { i.v.=1-29) }\end{array}$ & N. cit. & FR & N. taxa & FR \\
\hline \multirow{5}{*}{ 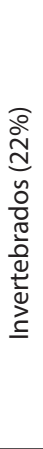 } & $\begin{array}{l}\text { Insetos (abelha/barata/barbeiro/besouro/cigarra/cupim/formiga/ } \\
\text { gafanhoto/grilo/larvas/lagarta/mariposa/maribondo/mosca/ } \\
\text { percevejos/piolho/vagalume/vespa/tesourinha/lacraia/louva-a- } \\
\text { deus/piolho-de-cobra) }\end{array}$ & 301 & $11,3^{*}$ & 164 & $11,5^{*}$ \\
\hline & $\begin{array}{l}\text { Invertebrados marinhos (acídia/água-viva/ coral/esponja/estrela- } \\
\text { do-mar/ouriço-do-mar/bolacha-do-mar/dólar-do-mar/camarão/ } \\
\text { caranguejo/barata-do-mar/tamarutaca/lagosta) }\end{array}$ & 113 & 4,2 & 61 & 4,3 \\
\hline & $\begin{array}{l}\text { Moluscos (lesma/caramujo/caracol/mexilhão/ostra/lesma-do-mar/ } \\
\text { polvo/lula) }\end{array}$ & 75 & 2,8 & 55 & 3,9 \\
\hline & Aracnídeos (aranha/escorpião/ácaro) & 14 & 0,7 & 11 & 1,1 \\
\hline & Anelídeos (minhoca/sanguessuga) & 4 & 0,2 & 2 & 0,2 \\
\hline \multirow{7}{*}{ 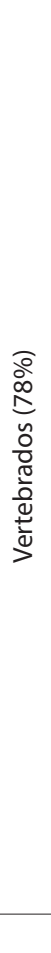 } & $\begin{array}{l}\text { Peixes (arraia/baiacu/bagre/bacalhau/cação/cavalo-marinho/ } \\
\text { moreia/cumbá/enguia/peixe-voador/piranha/pirarucu/poraquê/ } \\
\text { traíra/tubarão/ornamentais) }\end{array}$ & 413 & $15,5^{*}$ & 260 & $18,3^{*}$ \\
\hline & Anfíbios (sapo/rã/perereca/cobra-de-duas-cabeças) & 47 & 2,5 & 49 & 3,5 \\
\hline & $\begin{array}{l}\text { Répteis (tartaruga/cágado/jabuti/jacaré/lagartixa/lagarto/ } \\
\text { camaleão/salamandra) }\end{array}$ & 422 & $15,9^{*}$ & 199 & $14,0^{*}$ \\
\hline & $\begin{array}{l}\text { Aves (abutre/andorinha/águia/araçari/araponga/avestruz/ } \\
\text { beija-flor/anu/carcará/condor/cancão/cotinga/corvo/colibri/ } \\
\text { codorniz/ corrupião/ema/falcão/fim-fim/flamingo/garça/gavião/ } \\
\text { gralha-cancã/garça/ganso/galinha/guiné/jacu/jacumim/jaó/ } \\
\text { joão-de-barro/juriti/lavadeira/martim/mutum/papagaio/pardal/ } \\
\text { passeriformes/periquitos/pombos/pato/pavão/perdigão/peru/ } \\
\text { pica-pau/quero-quero/rolinha/sabiá/seriema/socó-boi/tico-tico/ } \\
\text { tordo/tucanos/urubus/zabelê) }\end{array}$ & 424 & $15,9^{*}$ & 251 & $17,7^{*}$ \\
\hline & $\begin{array}{l}\text { Mamíferos: Selvagens (anta/caititu/capivara/canídeos/castor/ } \\
\text { cutia/elefante/esquilo/gambá/gato-do-mato/guaxinim/lebre/ } \\
\text { lobo/lontra/leopardo/lince/macacos/morcegos/chimpanzé/gorila/ } \\
\text { quati/mocó/morcego/onça/paca/porco-espinho/preá/preguiças/ } \\
\text { raposas/roedor/tamanduá/tatus/ticaca/tigre/rinoceronte/ } \\
\text { urso/veado); Aquáticos (baleia/boto/foca/lontra/peixe-boi); } \\
\text { Domésticos (bode/boi/cachorro/vaca/burro/búfalo/carneiro/ } \\
\text { cavalo/cabra/chinchila/coelho/jegue/jumento/lhama/ovelha/ } \\
\text { porco). }\end{array}$ & 783 & $29,4^{*}$ & 346 & $24,4^{*}$ \\
\hline & Humano & 1 & 0,1 & 1 & 0,1 \\
\hline & Total & \multicolumn{2}{|c|}{2.662} & \multicolumn{2}{|c|}{1.420} \\
\hline
\end{tabular}

$\mathrm{N}$. cit. = total de citações; $\mathrm{n}$. taxa = total de táxons; $\mathrm{FR}=$ frequência relativa. $\mathrm{A}$ homogeneidade da amostra foi testada por meio da comparação dos valores absolutos no teste de aderência goodness of fit, sendo que os valores significativamente mais representativos estão acompanhados por asterisco.

Fontes: Figueiredo (1994); Guo et al. (1997); Marques (1997); Costa-Neto, Oliveira (2000); Almeida, Albuquerque (2002); Costa Pinto, Maduro (2003); Lev (2003); Silva et al. (2004); Alves, Rosa (2005); Andrade, Costa-Neto (2005); Costa-Neto, Pacheco (2005); Alves, Rosa (2006); González et al. (2016); Vazquez et al. (2006); Alves et al. (2007); Barboza et al. (2007); Alves et al. (2008a, 2008b); CostaNeto, Resende (2008); Moura, Marques (2008); Silva (2008); Alves et al. (2009); Ferreira et al. (2009); Alves, Dias (2010); Alves et al. (2010a, 2010b); Barbosa, Alves (2010); Costa-Neto, Motta (2010); Ulysséa et al. (2010); Costa-Neto (2011); Souto et al. (2011); Alves, Alves (2011); Alonso-Castro et al. (2011); Benítez (2011); Chakravorty et al. (2011); Song, Kim (2011); Alves et al. (2012); Bezerra et al. (2013); Betlu (2013); Ferreira et al. (2013); Kim, Song (2013); Martínez (2013); Alonso-Castro et al. (2011); Chellappandian et al. (2014); Mootoosamy, Mahomoodally (2014); Vallejo, González (2014); Hernandez, Campos, Borghi (2015); Vijayakumar et al. (2015); Vats, Thomas (2015); Nascimento et al. (2016). 
A caracterização da utilização dos animais foi baseada na análise de 1.482 citações, podendo se dar como um todo ou por meio da exploração de estruturas específicas, com destaque para tecidos internos, predominantemente o adiposo (Tabela 2).

Tabela 2: Frequência relativa das partes dos animais mais utilizadas como zooterápicos

\begin{tabular}{|c|c|c|}
\hline $\begin{array}{l}\text { Partes do corpo utilizadas } \\
\left(\mathrm{N}=1482-\mathrm{G}_{\text {test }(11)}=765 ; \mathrm{P}<0,0001\right)\end{array}$ & $\mathrm{N}$ & FR\% \\
\hline Tecidos internos (gordura/banha/sebo) & 318 & $21,5^{*}$ \\
\hline $\begin{array}{l}\text { Membros e apêndices externos (pernas/pé/ papo/rabo/esporão/tromba/chocalho/chifre/ } \\
\text { ferrão/escutelo/espinho/cauda/galhada/bico) }\end{array}$ & 190 & 12,8 \\
\hline $\begin{array}{l}\text { Órgãos internos (víscera/fígado/moela/cérebro/medula/língua/dentes/carne/estômago/ } \\
\text { coração/músculo) }\end{array}$ & 173 & 11,7 \\
\hline Animal inteiro (chá ou garrafada) & 347 & $23,4^{*}$ \\
\hline Excreções (estrume/urina/fezes/muco/suor) & 58 & 3,9 \\
\hline Revestimento (pele/couro/pelo/pena/casco/unha/carapaça/concha) & 126 & 8,5 \\
\hline Ossos & 78 & 5,3 \\
\hline Secreções (muco/saliva/bile/leite//teia/moléculas expelidas/veneno/toxina) & 33 & 2,2 \\
\hline Ovos (casca/ovo) & 20 & 1,3 \\
\hline Órgãos do aparelho reprodutivo (escroto/testículo/trompa/genitália/gônada/pênis) & 17 & 1,1 \\
\hline Simbologia (canto/presença) & 70 & 4,7 \\
\hline Ninhos (casulo/cupinzeiro/colmeia/cera/mel) & 52 & 3,5 \\
\hline
\end{tabular}

$\mathrm{FR}=$ frequência relativa. A homogeneidade da amostra foi testada por meio da comparação dos valores absolutos no teste de aderência goodness of fit, sendo que os valores significativamente mais representativos estão acompanhados por asterisco.

Fontes: Figueiredo (1994); Marques (1997); Costa-Neto, Oliveira (2000); Almeida, Albuquerque (2002); Lev (2003); Alves, Rosa (2005); Andrade, Costa-Neto (2005); Costa-Neto, Pacheco (2005); Alves, Rosa (2006); González et al. (2016); Alves et al. (2007); Barboza et al. (2007); Alves et al. (2008a, 2008b); Costa-Neto, Resende (2008); Moura, Marques (2008); Silva (2008); Alves et al. (2009); Ferreira et al. (2009); Alves, Dias (2010); Alves et al. (2010a, 2010b); Barbosa, Alves (2010); Costa-Neto, Motta (2010); Ulysséa et al. (2010); Costa-Neto (2011); Souto et al. (2011); Alonso-Castro et al. (2011); Betlu (2013); Benítez (2011); Chakravorty et al. (2011); Song, Kim (2011); Alves et al. (2012); Bezerra et al. (2013); Ferreira et al. (2013); Kim, Song (2013); Martínez (2013); Alonso-Castro et al. (2011); Chellappandian et al. (2014); Mootoosamy, Mahomoodally (2014); Vallejo, González (2014); Hernandez Campos, Borghi (2015); Vats, Thomas (2015); Nascimento et al. (2016).

A diversidade de espécies de animais e meios de utilização registrados pela sistematização da literatura atestou concomitantemente a expressividade da prática e a vinculação dos animais ao papel de recursos. A expressividade da zooterapia resiste ao tempo, à urbanização e ao desenvolvimento tecnológico, endossando sua importância como alternativa terapêutica, tal como atestado por Alves e Dias (2010). O presente estudo categorizou o uso de quase 1.500 espécies selvagens ou domesticadas como ingredientes curativos, protetivos ou preventivos, montante similar ao revelado em outras abordagens, como na medicina tradicional chinesa (MTC) (Guo et al., 1997; Alves, Rosa, 2005). Essa amplitude da prática demanda a aplicação dos princípios éticos da responsabilidade, cuidado e sustentabilidade no balizamento da relação homem/natureza, como defendido por Fischer et al. (2016a, 2016b, 2017) na análise de situações envolvendo o ecoturismo, a crise hídrica e a cinoterapia. Deve-se ressaltar que os argumentos favoráveis à exploração da fauna para benefício humano não se sustentam se há perda na qualidade de vida dos animais. Seja pelo impacto indireto, causado na estrutura das populações com reflexo em 
todo ecossistema, ou pelo impacto direto, na promoção de dor e sofrimento envolvidos na captura, criação, manejo e experimentação.

O impacto indireto nas populações faunísticas e o uso insustentável de animais na medicina são reconhecidos pela comunidade científica como ameaça à conservação da vida selvagem, pois, como atestado no levantamento, a maioria dos animais destinados a esse fim é silvestre e retirada diretamente da natureza. Segundo a análise de Ferreira et al. (2016), no Norte e Nordeste brasileiros, cerca de $86 \%$ dos animais utilizados como zooterapêuticos são selvagens. Muitas vezes o impacto afeta a estrutura das populações com consequente sofrimento, superexploração e potencialização de riscos de extinção (Anyinam, 1995; Still, 2003; Alves et al., 2007). Destaca-se nesse cenário a MTC, praticada há milênios, com contemporânea expressividade e expansão globalizada e que, de acordo com Guo et al. (1997) e Still (2003), já alcança 1/4 da população mundial. Essa vertente médica lança mão de fórmulas constituídas por tecidos, ossos, cornos, testículos e bile de inúmeros animais como tigre, antílope, búfalo, rinoceronte, cão, urso e cobra, geralmente combinados com ervas, mesmo sem a eficácia e a qualidade sanitária cientificamente atestadas. Assim, é um potencial meio de gerar vulnerabilidades no contexto ecológico, ético, legal e de saúde, decorrentes tanto da caça quanto da manutenção em cativeiro.

$\mathrm{O}$ argumento mais consistente na restrição da utilização de animais para finalidade medicinal diz respeito ao risco de extinção, sendo a principal orientação mitigadora a substituição por outras espécies. Contudo, Alves e Dias (2010) condicionaram a substituição a uma análise profunda de aspectos biológicos, ecológicos e etológicos dos animais disponíveis. Na maioria das localidades estudadas pelo fato de eles Ferreira et al. (2016), a substituição de animais selvagens por domésticos não é possível por atenderem a finalidades díspares. Contudo, os autores categorizaram os animais entre os passíveis ou não de substituição, sendo os últimos os mais susceptíveis e que, por isso, demandam estratégias de conservação. Análises anteriores à última lista brasileira de espécies ameaçadas, veiculadas por Almeida e Albuquerque (2002) e Alves et al. (2008a) apontavam que todos os primatas, $53 \%$ dos répteis e $23 \%$ das aves utilizados no comércio do Norte e Nordeste brasileiros se enquadravam em alguma das categorias de risco. Contudo, os dados levantados no presente estudo evidenciaram baixo compartilhamento de espécies constantes na lista de ameaçadas de 2014 e aquelas usadas na zooterapia. Esse resultado corrobora a inferência de Ferreira et al. $(2013,2016)$ de que o comércio brasileiro não é reconhecido como causa dos declínios populacionais de animais. Os autores ressaltaram algumas exceções, como a exploração do cavalo-marinho, igualmente atestada na presente categorização. Verificou-se também que espécies mais próximas dos humanos, tais como animais domesticados ou sinantrópicos, estão presentes na maioria das listagens. No entanto, as preocupações diante do risco em potencial levaram Souto et al. (2011) a salientar a importância do esforço de organizações como a Traffic e a Internacional Union for Conservation of Nature (UCN) nos registros dos usos tradicionais dos recursos faunísticos, com a finalidade de subsidiar o estabelecimento de políticas públicas que insiram a zooterapia no contexto da conservação da biodiversidade.

Mesmo diante do forte argumento do impacto da zooterapia na extinção de espécies, Alves e Dias (2010) ressaltaram que, aparentemente, a utilização médica tradicional da maioria das espécies, particularmente invertebrados, é pouco expressiva em termos de 
impactos ambientais em comparação à degradação ambiental ou à captura e à coleta para outras finalidades. Além disso, os autores alertaram que a maioria dos elementos empregados na medicina é subproduto de espécies exploradas para outras finalidades. Tal evidência é corroborada por Moura e Marques (2008), os quais enalteceram o uso medicinal justamente pela multiutilidade, sendo que 55\% dos elementos são subprodutos relativos a estruturas corporais impróprias para consumo alimentício ou confecção de artefatos, tais como chifres, dentes, unhas, ossos e gorduras. Segundo os autores, a rejeição dessas partes pode ser devida à concentração de substâncias bioativas que, se consumidas em grande quantidade, podem trazer danos. Consequentemente, esse costume é maximizado por um processo cultural e econômico que se apropria do recurso animal, muitas vezes rejeitado por classes mais ricas. Esse fato subsidia a proposta de Ferreira et al. (2016) de substituição do uso de animais selvagens por derivados da produção animal normalmente descartados, tais como gordura, peles e chifres.

Os impactos diretos da zooterapia advêm do fato de que, embora as pesquisas e produção de zooterápicos apresentem resultados positivos visíveis e economicamente viáveis, muitas vezes não é considerado o bem-estar do animal. Segundo Still (2003), o manejo e o meio da extração do produto terapêutico, o destino do animal após a extração dos ativos ou insumos, os possíveis danos e prejuízos ocasionados para a vida do animal e o grupo em que está inserido são alguns dos pontos que devem ser considerados. Costa-Neto (1999) alertou, ainda, para a necessidade de propiciar condições dignas ao testar os animais como remédio e sugeriu a busca de alternativas sintéticas. Essas questões adentram a área da ética animal, que tem refletido sobre as mudanças de paradigmas na relação com os animais. De uma maneira geral, segundo a sistematização apresentada por Fischer e Oliveira (2012), as abordagens éticas podem representar cunho utilitarista ou deontológico. Na primeira, insere-se a visão empregada no meio científico e na legislação, os quais, embasados nas ideias de Singer (2004), reconhecem a senciência animal e o princípio da igual consideração de interesses, de acordo com os quais animais não humanos compartilham com os humanos o interesse em não sofrer. Logo, consideram a legitimidade do uso de animais como recursos para os humanos, caso seja realmente necessário, em situações em que não exista outra alternativa e desde que se infrinja o menor sofrimento ao menor número possível de animais. Na segunda, o movimento do direito animal ou abolicionismo, representado por filósofos como Regan (2006) e Francione (2013), julga os procedimentos com o animal pelo que são, em vez das suas consequências. Consideram errado utilizar os animais como recursos para suprir necessidades ilegítimas, atribuindo o status moral a seres que detêm, além do interesse em não sofrer, o interesse em viver. Como sujeitos de uma vida, possuem valor intrínseco, não podendo o homem eximi-los do direito de não ser tratados como propriedade. Ressalta-se que, em ambos os casos, a ética animal ainda detém um viés especista, uma vez que incluiu como detentores de status moral apenas animais reconhecidamente sencientes, ao passo que exclui desse universo praticamente $90 \%$ da fauna representada por animais invertebrados.

O sucesso da zooterapia atribuído por Alves e Dias (2010) à sua acessibilidade, disponibilidade e eficácia foi contestado por Still (2003), que argumenta que crenças tradicionais não podem ser tomadas como evidências suficientes de eficácia. Segundo a 
autora, apesar de ser uma prática comum, estudos sistematizados ainda são escassos, o que dificulta o desenvolvimento de pesquisas sobre a fauna medicinal. Consequentemente, os órgãos competentes não são advertidos da necessidade de desenvolver estratégias e legislações específicas e imparciais que permitam alcançar um ponto de equilíbrio entre os interesses da sociedade e a preservação dos ecossistemas. Considerando que grande parte da preparação de remédios derivados de animais utiliza produtos obtidos após a morte do animal, Almeida e Albuquerque (2002) e Souto et al. (2011) pontuaram como fundamental a conscientização. Inferência que corrobora a visão de Costa-Neto (1999) de que a exploração ética de recursos faunísticos como meio alternativo para cura de enfermidades só será viável com a inclusão da zooterapia como elemento primordial do desenvolvimento sustentável. Para tal, Alves et al. (2007, 2008a) e Lima e Santos (2010) reforçaram que é imprescindível que se conheçam as espécies utilizadas, assim como a estrutura populacional, estado de conservação e aspectos da biologia, ecologia e etologia de cada uma, a fim de que seja possível estabelecer prioridades e estratégias de conservação e produção sustentável de diferentes animais.

No Brasil, a legislação que protege os animais é rigorosa e complexa. Está representada principalmente pela Lei de Crimes Ambientais (Brasil, 12 fev. 1998), pela Lei Arouca (Brasil, 8 out. 2008) e pela Lei da Biodiversidade (Brasil, 20 maio 2015). A Lei de Crimes Ambientais criminaliza todo aquele que matar, perseguir, caçar, apanhar, utilizar espécimes da fauna silvestre, nativos ou em rota migratória, sem a devida autorização. Soma-se a isso a punição da procriação, transporte, venda e exportação de ovos, larvas ou espécimes da fauna ou de produtos e objetos dela oriundos, provenientes de criadouros não autorizados ou sem a devida permissão; introdução de espécies exóticas sem autorização; modificação, dano ou destruição de ninho, abrigo ou criadouro natural. O crime é agravado se praticado contra espécie ameaçada de extinção, em período proibido à caça ou à pesca, à noite, em unidade de conservação e com emprego de métodos ou instrumentos capazes de provocar destruição em massa; se decorre do exercício de caça profissional e se há ato de abuso e maus-tratos. A lei só não criminaliza aquele que abate o animal em caso de fome ou proteção mediante eventuais danos à saúde, a lavouras ou a bens materiais, contudo, esses igualmente devem ser monitorados por órgãos específicos. Já a Lei Arouca é composta por 33 resoluções normativas, seis orientações técnicas, além de decretos e portarias (Concea, 2015). Esses instrumentos visam à normatização da produção, manutenção e utilização de animais em atividades de ensino ou pesquisa, intermediadas pela aplicação do princípio dos 3Rs - reduzir, reutilizar e reciclar - subordinada à avaliação e ao monitoramento por uma Comissão de Ética no Uso de Animais (Ceua) (Fischer, Oliveira, 2012). O princípio dos 3Rs visa minimizar o uso de animais, fomentar a substituição por espécies menos sencientes e por métodos alternativos e refinar os procedimentos, tornando todo o processo o menos invasivo possível e diminuindo ao máximo a promoção de dor e sofrimento ao animal (Fischer, Oliveira, 2012). Contudo, mesmo diante do fato de a fauna ser considerada patrimônio natural e, portanto, tutelada pelo Estado e indisponível para utilização por qualquer pessoa e de qualquer forma, essas regulamentações não são suficientes para coibir os procedimentos incorporados pela sociedade, conduzindo para a ilegalidade a prática da zooterapia. 


\section{Caracterização dos atores representantes da sociedade como agentes morais no uso de animais como zooterápicos}

A inserção dos setores representantes da sociedade como agentes morais no uso de animais como medicamentos pressupõe uma decisão racional, compressão das conseqüências para todos os envolvidos na questão, apoiada em uma argumentação balizada por princípios éticos. Entretanto, muitas vezes prevalecem nesse contexto aspectos biológicos, evolutivos e culturais consolidados em inúmeras sociedades, cuja decisão não é fruto de uma reflexão, mas reflexo de um comportamento incorporado, como pode ser atestado na análise quantitativa do presente estudo.

A categorização dos dados atestou a incorporação dos animais para finalidade de saúde e estética. Com relação à saúde, a análise das referências científicas resultou em 2.413 citações agrupadas em cinquenta finalidades, referentes principalmente a problemas motores e respiratórios (Tabela 3). Devido a sua alta frequência e ao incômodo que geram, esses problemas demandam interferência rápida, que pode ser inviabilizada pela inacessibilidade a auxílio médico ou pela necessidade de maior investimentos na aquisição de medicamentos.

Tabela 3: Frequência relativa de referências do uso de animais para tratamento de saúde

\begin{tabular}{|c|c|c|}
\hline $\begin{array}{l}\text { Problemas de saúde para os quais são direcionados animais } \\
\qquad\left(\mathrm{N}=2413 \mathrm{G}_{\text {test(13) }}=1522 ; \mathrm{P}<0,00001\right)\end{array}$ & $\mathbf{N}$ & FR \\
\hline $\begin{array}{l}\text { Problemas motores (coluna/artrose/reumatismo/osso/músculo/ lesão/fratura/contusão/ } \\
\text { torção) }\end{array}$ & 380 & $15,7^{*}$ \\
\hline Problemas respiratórios & 495 & $20,5^{*}$ \\
\hline Problemas infecciosos (bactéria/vírus/fungo/febre) & 174 & 7,2 \\
\hline Problemas inflamatórios & 212 & 8,8 \\
\hline $\begin{array}{l}\text { Problemas no tecido de revestimento (ferida/fissura/queimadura/mucosa/gengiva/verruga/ } \\
\text { dente/unha) }\end{array}$ & 240 & 9,9 \\
\hline Problemas circulatórios (hemorroida/variz/inchaço/AVC/derrame/anemia/ diurético) & 162 & 6,7 \\
\hline Problemas em órgão sensoriais & 70 & 2,9 \\
\hline Problemas neurológicos (enxaqueca/vícios/alcoolismo) & 142 & 5,9 \\
\hline Estimulantes (fortificante/afrodisíaco) & 83 & 3,4 \\
\hline Problemas em órgãos internos (gastrointestinal/fígado/rim/coração) & 126 & 5,2 \\
\hline Atenuantes de agentes externos (picada/espinho/repelente/intoxicação) & 91 & 3,8 \\
\hline Questões de superstição e simpatias & 123 & 5,1 \\
\hline Câncer (tumor/nódulo) & 36 & 1,5 \\
\hline $\begin{array}{l}\text { Questões relacionadas ao sexo feminino (doenças da gravidez/cólica/problemas } \\
\text { menstruais/problemas no parto/pós-parto/abortivo/contraceptivo) }\end{array}$ & 79 & 3,3 \\
\hline
\end{tabular}

$F R=$ frequência relativa. A homogeneidade da amostra foi testada por meio da comparação dos valores absolutos no teste de aderência goodness of fit, sendo que os valores significativamente mais representativos estão acompanhados por asterisco.

Fontes: Figueiredo (1994); Marques (1997); Costa-Neto, Oliveira (2000); Almeida, Albuquerque (2002); Lev (2003); Alves, Rosa (2005); Andrade, Costa-Neto (2005); Costa-Neto, Pacheco (2005); Alves, Rosa (2006); González et al. (2016); Alves et al. (2007); Barboza et al. (2007); Alves et al. (2008a, 2008b); Costa-Neto, Resende (2008); Moura, Marques (2008); Silva (2008); Alves et al. (2009); Ferreira et al. (2009); Alves, Dias (2010); Alves et al. (2010a, 2010b); Barbosa, Alves (2010); Costa-Neto, Motta (2010); Ulysséa et al. (2010); Costa-Neto (2011); Souto et al. (2011); Alonso-Castro et al. (2011); Betlu (2013); Benitez (2011); Chakravorty et al. (2011); Song, Kim (2011); Alves et al. (2012); Bezerra et al. (2013); Ferreira et al. (2013); Kim, Song (2013); Martínez (2013); Alonso-Castro et al. (2011); Chellappandian et al. (2014); Mootoosamy, Mahomoodally (2014); Vallejo, González (2014); Hernandez, Campos, Borghi (2015); Vats, Thomas (2015); Nascimento et al. (2016). 
A incorporação dos animais à estética também indicou uma relação com a manutenção corporal que ultrapassa a mera busca de juventude e beleza, já que acabam por favorecer cuidados que beneficiam a saúde. Esse tipo de conduta é mais frequente em populações com baixo acesso a cosméticos industrializados. Foram categorizadas 65 referências informais, relacionadas a 19 animais, com destaque para: muco de caramujo $(12,3 \%)$, mel e toxinas de abelhas (11\%), toxinas e massagem por cobras (9\%), leite de vaca e de cabra $(7,7 \%)$, sangue e células-tronco humanos (7,7\%), placenta de ovelha $(7,7 \%)$, fezes de pássaros $(7,7 \%)$, massagem por peixes e sanguessugas $(13,8 \%)$, esperma de touro $(4,6 \%)$; teia de aranha, esponja do mar, formiga, ostras e ovos de galinha, com 3,1\% cada, e crista de galo e embrião de pato, com 1,5\% cada. Secreções, partes ou o animal inteiro podem ser usados para tratamentos faciais $(73,8 \%)$, capilares $(12,3 \%)$, corporais $(7,7 \%)$ ou fisiológicos $(6,2 \%)$. Eles podem ser usados diretamente sobre o corpo $(34,4 \%)$, macerados em máscaras $(34,4 \%)$, em forma de creme $(26,6 \%)$ ou injetável $(4,7 \%)$. Sua ação foi relacionada a 11 propriedades congregando 114 registros, dos quais se destacam: ação esfoliante $(22,9 \%)$, hidratante $(16,5 \%)$, estimulante na produção de colágeno $(15,6 \%)$, antioxidante $(13,8 \%)$, relaxante $(7,3 \%)$, circulatória $(7,3 \%)$, antibactericida $(5,5 \%)$, anti-inflamatória $(4,6 \%)$, promotora do crescimento celular (4\%) e paralisante muscular $(1,8 \%)$.

O segmento social consultado, conforme o esperado, não correspondeu aos dados da literatura que foca em populações rurais, caracterizando uma população específica com acesso à internet e principalmente de Curitiba, cuja maioria (98,1\% de 278) afirmou já ter utilizado algum chá ou remédio caseiro composto por plantas, mas ninguém se referiu a animais. Quando questionado diretamente sobre o conhecimento do uso de animais invertebrados para produção de medicamentos ou cosméticos, apenas $26 \%$ do grupo avaliado mostrou deter informações, porém de cunho científico e industrial, uma vez que citou predominantemente: abelhas (28\%), aranhas (19\%), moluscos (14\%), cochonilhas (12\%) ecrustáceos (8\%). Insetos em geral, borboleta, carrapato, escorpião, formiga, ostra, cavalo e cobra representaram individualmente $2 \%$ das respostas. Os animais citados foram atrelados à finalidade do uso de toxinas para produção de medicamentos e analgésicos (24\%), como corantes (30\%), na produção de cosméticos (11\%), de antídotos para venenos (9\%), para produção de nanquim (4\%) e para extração de iodo, ômega, produção de pomadas, seda e na cinoterapia e equinoterapia, cada um desses com $2 \%$.

\section{Argumentos biológicos e etológicos dos atores representantes da sociedade}

Os dados do levantamento quantitativo atestaram que o consumo de animais está inserido no contexto de inter-relação homem/natureza, intencionando tanto a manutenção nutricional quanto o reequilíbrio de demandas específicas em decorrência de uma doença ou debilidade. O que se justifica devido ao fato de os seres vivos possuírem a mesma constituição bioquímica e utilizarem os mesmos processos metabólicos que os nivelam molecular, bioquímica e, é provável, quanticamente (Lipton, 2007). Moura e Marques (2008) consideraram o fato de as sociedades humanas terem sido construídas fundamentadas por processos evolutivos que viabilizaram a sobrevivência dos ancestrais. Logo, o estabelecimento do comportamento de ingerir outros seres vivos para restauração 
de processos fisiológicos constitui uma estratégia de sobrevivência para situações de emergência, que podem estar relacionadas a catástrofes naturais, assim como a guerras e ao terrorismo. Isso possibilita a superação de situações hostis por meio da exploração dos recursos locais. Assim, a medicina popular se consolidou pelo aprendizado por meio do condicionamento operante de tentativa e erro, selecionando indivíduos com maior capacidade adaptativa de incorporar novas espécies ao seu repertório medicinal. Fato provavelmente refletido na ausência de universalidade, uniformidade e consenso aferida por Almeida e Albuquerque (2002) na comparação da zooterapia praticada entre diferentes comunidades e subsidiada pela categorização do presente estudo, que atestou a citação de mais da metade dos animais em apenas um artigo científico e, automaticamente, sua vinculação a usos específicos em locais específicos.

\section{Argumentos culturais dos atores representantes da sociedade}

A forma como as sociedades se relacionam com o meio natural depende das representações traçadas por valores culturais e experiências individuais. Esses, segundo Morin (2003) e Bauman (2011), devem ser reconhecidos, uma vez que, embora as pessoas inseridas nas sociedades contemporâneas possuam as mesmas demandas biológicas que os seus ancestrais neolíticos, os desafios promovidos pelas novas estruturas sociais e econômicas conduzem a sérios problemas biopsicossociais, reflexos de uma vida artificial motivada por uma estrutura capitalista e individualista. Moura e Marques (2008) basearam-se na teoria das assinaturas - a ideia de que semelhante cura semelhante - para justificar o uso medicinal dos animais, uma vez que essa teoria associa sua morfologia e sua semelhança com os humanos como evidência de suas propriedades terapêuticas.

A zooterapia é adotada há séculos por inúmeras culturas, mesmo sendo o conhecimento de animais medicinais considerado mais idiossincrático do que o das plantas, como assinalam Almeida e Albuquerque (2002). Autores como Alves e Rosa (2005), Albuquerque e Hanazaki (2006) e Alves et al. (2008a) relacionaram a utilização medicinal dos animais a conceitos etiológicos que envolvem uma complexa visão cosmológica do processo de cura, a qual se vincula principalmente com a conotação de magia, superstições e prática religiosa. Moura e Marques (2008) legitimaram a zooterapia considerando que o conhecimento popular pode funcionar como um atalho para o acesso científico a novas terapias. Como exemplo, citaram a comprovação do uso de pele e secreções das glândulas parótidas de sapos para regular funções corporais e fertilidade, assim como a tendência popular de consumir ômega 3. Contudo, Silva (2008) argumentou que esses casos de sucesso não dispensam a necessidade de aprofundamento científico na relação entre crenças populares e o uso de zooterápicos, importante para fornecer mais segurança contra potenciais riscos aos quais os usuários da medicina tradicional podem estar expostos.

No Brasil, Alves et al. (2007) observaram que a heterogenia cultural e as desigualdades sociais favorecem as práticas zooterapêuticas desde a época colonial, mas estudos científicos relacionados com a etnozoologia são escassos. Para Alves e Rosa (2005) tal carência, somada à globalização e à consequente miscigenação cultural, ameaça a manutenção de informações importantes para estudos etnobiológicos, tanto dentro das comunidades quanto nas 
relações econômicas e ecológicas estabelecidas entre elas. Anyinam (1995) e Silva (2008) pontuaram a possibilidade de extinção do etnoconhecimento como possível consequência da falta desses estudos e de conservação desse conhecimento, indicando como causas a sua substituição pela medicina ocidental e o êxodo rural. Isso pode impactar a medicina moderna e minimizar os potenciais benefícios que as gerações futuras poderiam auferir dos canais de interação com a natureza.

\section{Argumentos sociais dos atores representantes da sociedade}

A diversidade social reserva um papel importante para a etnomedicina, pois o uso de animais e plantas na atenção primária à saúde pode ser uma opção relevante de tratamento para pessoas que não dispõem de recursos para outras terapias. $\mathrm{O}$ uso de medicamentos produzidos a partir de animais é muito comum em zonas mais carentes, onde os custos dos medicamentos industrializados não condizem com a realidade socioeconômica. No entanto, para Alves e Rosa (2005) e Alves et al. (2007, 2008a), o problema social atrelado à zooterapia ultrapassa a inerente inacessibilidade rural, alcançando a realidade de desigualdades sociais urbanas resultantes do inchaço populacional. Dessa forma, demandando o retorno ao natural, evidenciando a manutenção das conexões com a cultura e com os valores tradicionais.

\section{Argumentos ecológicos dos atores representantes da sociedade}

A importância da etnomedicina ultrapassa os registros histórico e cultural, a compreensão da relação humano/natureza e a compreensão da utilização dos animais como recursos medicinais. Uma vez que o elo entre a natureza e a cultura remete a uma aplicação imediata na conservação, tanto dos ecossistemas quanto do patrimônio cultural, os quais se retroalimentam (Anyinam, 1995, Alves et al., 2012). Alves et al. (2007) ressaltaram que as populações humanas dependem da natureza para a sua integridade biopsicossocial, mas podem causar impactos na produtividade do ecossistema e na estrutura das populações dos animais, os quais, somados a outras formas de destruição, degradação e poluição podem conduzir à extinção de espécies, colocando também em risco o conhecimento tradicional. A etnomedicina não é imune à crise ambiental. O fato de determinados cultos e rituais protegerem certos animais não basta para deter sua exposição à possível extinção. Logo, para Anyinam (1995), a preservação de culturas tradicionais pode ser uma aliada importante na conservação de remanescentes florestais e comunidades bióticas, constituindo um aspecto relevante para a prática da sustentabilidade. Por exemplo, Silva (2008) atestou que algumas comunidades, como os ribeirinhos do rio Negro, perpetuam a crença de que a transgressão de determinadas regras de regulação da caça e pesca pode provocar doenças espirituais. Segundo Lima e Santos (2010), a sustentabilidade sociocultural demanda uma abordagem multidimensional que presume a compreensão de como os povos percebem, usam, manejam, valorizam e transferem seus conhecimentos. Dessa forma, Ferreira et al. (2016) ponderaram que não basta avaliar a substituição de animais selvagens por plantas ou animais domésticos se não forem considerados os aspectos culturais e simbólicos dos seus usos e significados para a comunidade. 


\section{Atores representantes da economia como agentes morais no uso de animais como zooterápicos}

Os atores representantes da economia se inserem como agentes morais nas decisões de como e quando utilizar os animais como recurso medicinal, e o quanto deles utilizar, a partir de uma ponderação do custo e benefício da prática. O sistema econômico possui múltiplos atores, motivados por interesses e valores próprios, que podem trazer desequilíbrio. O consumidor, o produtor, o atravessador, o comerciante e o sistema industrial se mobilizam em diferentes frentes, retroalimentando o fluxo do processo envolvido com a zooterapia.

O mercado informal, segundo Anyinam (1995) e Alves e Rosa (2005), tem absorvido as demandas por zooterápicos. As severas legislações locais e internacionais direcionam a prática da zooterapia para a ilegalidade. Isso aumenta ainda mais o valor de partes do corpo de determinados animais, principalmente os mais raros, como rinocerontes, ursos e espécies ameaçadas, incentivando a caça ilegal e o tráfico internacional, que mobiliza bilhões de dólares por ano.

O consumidor de remédios produzidos com animais não tem um perfil socioeconômico claro, embora os comerciantes estudados por Almeida e Albuquerque (2002) e Costa Pinto e Maduro (2003) tenham sido caracterizados como indivíduos com acesso restrito e pouco qualificados para os cuidados com a saúde. Em geral, apresentam baixo nível de educação formal, são mais velhos e influenciados por fatores socioculturais e conhecimentos ligados à rede familiar (Alves, Rosa, 2005; Alves et al., 2007). É justamente a existência de consumidores que, em geral, não atenta aos meios utilizados para obtenção do produto que justifica a exploração econômica dos zooterápicos. Essa postura reforça o caráter individualista e materialista dos sujeitos contemporâneos, cujo consumismo, como mostra Bauman (2011), preza resultados rápidos e produtos descartáveis, alheios às questões que saiam do seu espectro de interesse ou benefício direto. Contudo, cabe ressalvar que, muitas vezes, o uso de animais é uma terapia menos tóxica, mais natural e eficaz que as terapias convencionais, com um custo mais baixo.

Os comerciantes disponibilizam uma ampla variedade de opções de zooterápicos. Apenas em Manaus, Almeida e Albuquerque (2002) identificaram partes do corpo de 97 espécies. Embora haja uma crença de que o comércio seja lucrativo, Costa Pinto e Maduro (2003) não identificaram ligação entre lucro e ramo de trabalho do comerciante de zooterápicos de Boa Vista, Roraima. Segundo os autores, muitos deles compreendem como uma obrigação moral e social usar seus conhecimentos para ajudar outras pessoas. Já Alves e Rosa (2005) registram o rendimento de quatro a cinco salários mínimos mensais entre os comerciantes no Norte e Nordeste do Brasil, o que é considerado razoável diante da realidade regional, cujos dados do IBGE apontam para 2015 um salário médio de 726 reais. Deve-se ater ao fato de que o aumento paulatino de pessoas aderindo a esse ramo de comércio reflete a disponibilidade de consumidores. Alves e Rosa (2005) consideram igualmente fundamental levar em conta o papel dos atravessadores, que muitas vezes são cientes da ilegalidade da prática.

A entrada em cena de processos industriais na produção de alimentos e medicamentos questionou a utilização do produto in natura, alegando a falta de controle na qualidade e quantidade do que está sendo consumido (Adami, Chemin, França, 2014). Assim, a produção controlada visou à manipulação de compostos específicos, somada à emergente 
legislação protetora da fauna, a qual também limitou o acesso às fontes dos princípios ativos em estado natural.

Nas últimas décadas, o setor farmacêutico vem apresentando um considerável crescimento econômico e de status no mercado, com consequente aumento na concorrência entre os laboratórios de pesquisa e produção. Concomitantemente, a repercussão de efeitos teratogênicos ocasionados por medicamento como a talidomida conduziu à elaboração de leis destinadas a garantir o cumprimento do controle de qualidade por meio da execução de testes de eficiência e segurança normatizadas e fiscalizadas pela OMS (Adami, Chemin, França, 2014). A aliança entre a expansão econômica e tecnológica das indústrias e o desejo humano de longevidade e juventude incentivou no segmento farmacêutico a ânsia pela descoberta e exploração dos recursos naturais. Segundo dados levantados por Still (2003) e Alves e Rosa (2005), cerca de 50\% das drogas bioativas são constituídas por componentes de espécies não humanas, um reflexo desses processos. Contudo, Albuquerque e Hanazaki (2006) apontaram que a qualidade da pesquisa sobre etnomedicina pode ser um empecilho para consolidação do conhecimento e transformação em produto. Segundo os autores, muitas publicações apresentam problemas éticos, metodológicos, resultados pobres para incorporação pela indústria, limitando-se à contribuição como registro documental.

Apesar de a medicina tradicional atender às necessidades básicas de saúde como atestam Alves et al. (2007), o uso de animais como recursos terapêuticos esbarra na falta de uma legislação específica, tais como as existentes para as plantas. No Brasil, a Política Nacional de Medicamentos (MS, 2001) e a Política Nacional de Práticas Integrativas e Complementares (MS, 2006) apoiam pesquisas sobre o potencial terapêutico da flora e da fauna. Contudo, a comercialização de fitoterápicos está atrelada à autorização de funcionamento da empresa e ao registro de produtos junto aos órgãos competentes da Agência Nacional de Vigilância Sanitária (Anvisa), ao atendimento à regulamentação ambiental por meio de registro nos órgãos ambientais e à regulamentação sanitária expressa nas normativas e portarias municipais, estaduais e federais. A legislação que trata de zooterápicos é ainda um campo pouco explorado. Deve ser rapidamente tratado pelas políticas públicas para evitar e minimizar impactos negativos ao ecossistema, assim contribuindo para preservar a biodiversidade, respeitar os aspectos socioeconômicos e culturais e para a melhoria da qualidade de vida.

As informações escassas e a legislação deficiente promovem dúvidas nos profissionais da saúde quanto à eficácia e à segurança do uso de zooterápicos. Até mesmo a comercialização do mel e seus derivados, considerados os zooterápicos mais reconhecidos historicamente no contexto popular e científico, gera dubiedade na regulamentação. A instrução normativa n.9 da Anvisa (17 ago. 2009) atesta que as farmácias podem comercializar mel, própolis e geléia real, desde que estejam regularizados no Ministério da Agricultura, Pecuária e Abastecimento (Mapa), uma vez que são considerados alimentos. Contudo, produtos obtidos de glândulas, órgãos, tecidos ou secreções de animais podem ser registrados na Anvisa como opoterápicos e, assim, tratados como medicamentos (Anvisa, 17 ago. 2009).

$\mathrm{O}$ registro de medicamentos na Gerência-geral de Medicamentos da Anvisa é um processo complexo. Requer um dossiê que engloba análise farmacotécnica com verificação de todas as etapas de fabricação, aquisição dos materiais, produção, controle de qualidade, liberação, 
estocagem, expedição de produtos, controles de eficácia e segurança e estudos pré-clínicos e clínicos (Adami, Chemin, França, 2014). Tais processos devem estar de acordo com condições de higiene adequadas. Essa exigência muitas vezes incompatibiliza o uso dos zooterápicos. Em pesquisa realizada no Nordeste brasileiro, Alves et al. (2007) identificaram condições sanitárias precárias dos produtos zooterápicos comercializados, tornando necessárias medidas de contenção de contaminações microbiológicas. Caso esses produtos não utilizem conservantes, a validade é extremamente limitada, uma vez que a Farmacopeia homeopática (Anvisa, 2011) estipula um prazo de apenas 48 horas para homeopáticos à base de água. $\mathrm{O}$ documento adverte que, no caso de os medicamentos conterem animais ou seus derivados como princípios ativos, deve-se atentar para o agravante de poderem conter microrganismos da própria espécie ou instalados em decorrência do manuseio inadequado, os quais podem proliferar rapidamente e até mesmo tornar-se letais.

O farmacêutico é o profissional capacitado no desenvolvimento, manipulação e dispensação de medicamentos. O código de ética da profissão prevê o dever de atuar com respeito à vida humana e ao ambiente, ou seja, não deve promover qualquer tipo de discriminação, deve agir em observância de sua responsabilidade social e não permitir a promoção, prevenção e recuperação da saúde com fins meramente comerciais. É um direito desse profissional recusar-se a receber qualquer tipo de mercadoria ou produto que não possua rastreabilidade ou não apresente informações claras e precisas sobre os tipos e quantidade de substâncias ativas contidas. Além disso, o código de ética farmacêutica proíbe promover a utilização ou a comercialização de substâncias ou produtos que não tenham a indicação terapêutica aprovada, que não estejam descritos na literatura científica e reconhecidos pelo órgão sanitário federal (CRF-PR, 2014). Essa normativa inviabiliza a comercialização dos zooterápicos em estabelecimentos farmacêuticos. Segundo a resolução n.67 (Anvisa, 8 out. 2007), todas as matérias-primas utilizadas para manipulação de medicamentos e cosméticos devem possuir especificações técnicas autorizadas e datadas. O estabelecimento deve, ainda, realizar periodicamente novos ensaios para confirmação das especificações da farmacopeia, obtidas de fornecedores qualificados, que possuam comprovação de regularidade perante as autoridades sanitárias competentes. Além disso, a farmácia deve realizar controle de qualidade interno e externo para certificar-se de que as informações contidas nos laudos do fornecedor são idôneas (Anvisa, 30 mar. 2007).

Deve-se considerar que alguns medicamentos homeopáticos podem conter derivados de animais (inteiros, partes, frescos ou secos, vivos ou mortos) ou seus produtos fisiológicos, patológicos, bactérias ou toxinas, órgãos doentes, frescos ou secos ou suas secreções. Para trabalhar com esse tipo de medicação, a farmácia ou indústria deve seguir a descrição encontrada nas farmacopeias, além de verificar se as substâncias utilizadas são reconhecidas pela Anvisa (30 mar. 2007).

\section{Princípios éticos envolvidos nas vulnerabilidades inerentes aos zooterápicos}

A promoção da zooterapia justifica-se pela possibilidade de melhorar a qualidade de vida ou até mesmo de possibilitar a superação de um problema que coloca o indivíduo em risco. Contudo, ressalva-se a necessidade de a zooterapia ser fundamentada por princípios 
éticos comuns às sociedades e à natureza, mesmo diante da aplicação da ética utilitarista da etnociência (Anyinam, 1995).

O uso de animais como medicamentos constitui uma questão complexa que requer a identificação dos agentes e pacientes morais envolvidos, bem como das vulnerabilidades, fundamentais na avaliação dos valores, princípios éticos e argumentos de todos os atores participantes. A análise qualitativa da literatura consultada permitiu traçar o panorama sintetizado na Figura 1. Devido à magnitude das vulnerabilidades, corrobora-se a inferência

Figura 1: Valores, princípios éticos e argumentos envolvidos no uso de zooterápicos

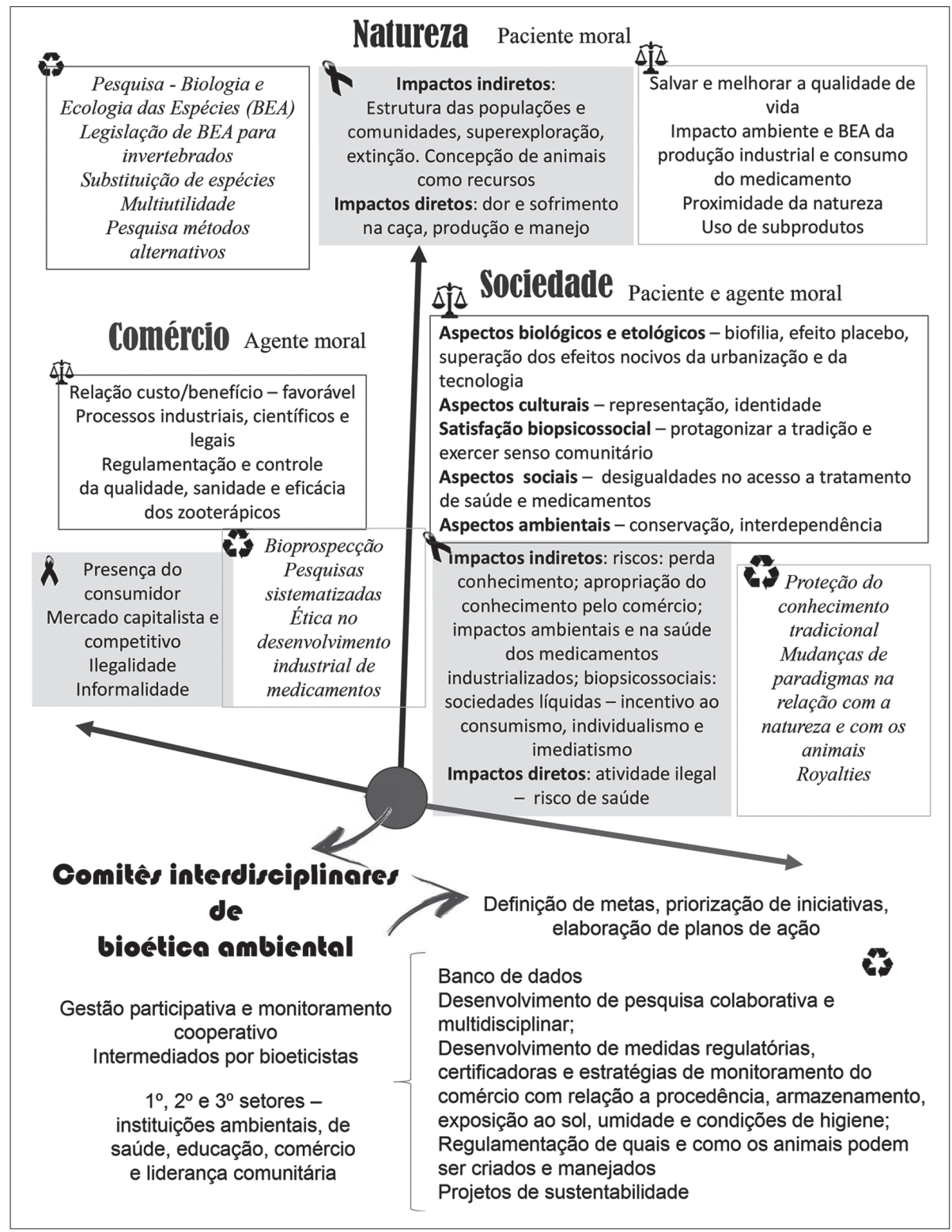

Fonte: elaborado pelas autoras. 
de Liu e Gu (2011) e Alves e Rosa (2005), segundo a qual se faz necessária a intervenção da legislação, que, aliada a preceitos éticos e morais, deve assegurar a custódia do conhecimento tradicional e protegê-lo, assim como preservar a natureza, prevenindo a apropriação por setores ilegítimos e a ação motivada por interesses puramente econômicos.

A relação do cidadão contemporâneo com o medicamento ultrapassa a mera manutenção da saúde; reflete inúmeras representações e motivações psicossociais. O mercado capitalista, representado pela indústria farmacêutica, aproveita-se da situação de vulnerabilidade emocional para comercializar o equilíbrio e a felicidade. Dessa forma, segundo Quirino (2015), apropria-se do etnoconhecimento para suprir as novas demandas sociais. Bauman (2011) denominou essa nova constituição social "sociedade líquida", na qual os valores éticos e morais estão sendo dissipados em prol de um incentivo ao consumo e ao individualismo, com elevados custos à saúde física e mental dos cidadãos. Segundo o sociólogo polonês, o mundo tem evidenciado um vazio existencial que resulta no surgimento de novas doenças psicossomáticas supridas pelo consumo de produtos e serviços, incluindo os tratamentos médicos e estéticos. A indústria farmacêutica guia suas pesquisas e produção visando ao lucro e, assim, negligencia inúmeras doenças de pouca expressividade.

O acesso à saúde deve atender aos princípios éticos da vulnerabilidade, do cuidado e da benevolência (Boff, 2003). Logo, é necessário levar em conta que os indivíduos estão cada vez mais expostos aos riscos decorrentes da destruição e contaminação ambientais. Nesse contexto, a administração do medicamento como paliativo para as consequências, em vez da intervenção nas causas, leva à maximização do seu uso. Esta, por sua vez, resulta em efeitos colaterais, diminuição da eficácia, além de resíduos de produção e consumo serem potenciais contaminantes ambientais. Nesse cenário, o acesso a medicamentos naturais e culturalmente contextualizados poderia ser uma alternativa apoiada no princípio ético do mal menor, uma vez que poderia resultar em impactos menores, além de remeter à proximidade com a natureza.

O fato de a legislação não contemplar a prática é interpretado por Still (2003), Alves et al. (2007) e Souto et al. (2011) como um meio de conduzi-la para a clandestinidade. A ausência de registros e de monitoramento da extração e comercialização de animais e partes de animais expõe o consumidor a riscos de contaminação e transmissão de zoonoses como salmonelas, tuberculose, raiva e alergias, além de favorecer o consumo de produtos de baixa qualidade. Alves et al. (2007) argumentaram que apenas a proibição legal é insuficiente para coibir a prática. Pelo contrário, maximiza as chances de causar impactos ambientais e de saúde. Almeida e Albuquerque (2002) reconheceram que a insegurança da zooterapia reside no fato de estar alicerçada na clandestinidade, o que legitima a captura e a coleta ilegais de animais da natureza e as insatisfatórias condições sanitárias.

A vulnerabilidade da natureza demanda, como recomendam Alves et al. (2008a), a necessidade de compreender quais animais são utilizados, seus biomas, status de conservação e como são processados na cadeia que os transforma em produtos terapêuticos. Nesse contexto, sobressai a questão de a sociedade não considerar igualmente os interesses dos animais e dos humanos nas situações em que os primeiros são usados para benefício dos últimos, assim comprometendo os princípios da responsabilidade e 
da sustentabilidade (Singer, 2004). Isto pode levar à drástica diminuição de populações de algumas espécies, incluída a extinção, ou expô-las a tratamentos cruéis. É importante ressaltar que a legislação que normatiza e regulamenta o uso de animais para pesquisa engloba apenas os vertebrados (Brasil, 8 out. 2008), incentivando sua substituição por invertebrados (Concea, 2015). Contudo, o presente estudo identificou que apenas 20\% das espécies catalogadas são invertebrados e que somente duas delas compõem a lista de espécies ameaçadas de 2014 (Brasil, 17 dez. 2014), o que reforça o alerta de Almeida e Albuquerque (2002) e Alves et al. (2008b) de que esses dados são suficientes para clamar pela importância de conservar essa categoria de animais.

A vulnerabilidade do etnoconhecimento foi identificada por Liu e Gu (2011) na MTC, alertando para a necessidade de proteção do conhecimento e o direito das populações nativas. Os autores interpretaram a literatura, artefatos, instrumentos e regras como patrimônio cultural, reconhecido pelo público doméstico e internacional. Segundo os autores, a MTC ultrapassa o mero registro de fórmulas, compartilhando conhecimento sobre a vida e englobando fenômenos como nascimento, crescimento, corpo físico e mental, saúde e doença. A seleção etnofarmacológica de elementos terapêuticos da fauna e da flora de uma região pode levar a valiosas descobertas científicas, incluindo novos fármacos ou identificação de mecanismos ainda desconhecidos de fármacos existentes. Entretanto, sobressaem posicionamentos contrários, como o de Still (2003), segundo o qual o uso medicinal dos animais não mais encontra justificativas em uma sociedade globalizada e tecnológica, imersa em alternativas terapêuticas, tampouco apresenta sustentabilidade. $\mathrm{O}$ autor alertou mesmo para o risco de se partilhar achados da MTC com um público leigo, que muitas vezes se encontra alheio às determinações éticas e legais e pode descontextualizar as citações históricas.

As questões éticas envolvidas com a zooterapia referem-se também à exploração da biodiversidade. Segundo Albuquerque e Hanazaki (2006) e Alves e Dias (2010), a bioprospecção deve acompanhar a manutenção e o manejo da diversidade de animais, pessoas, culturas e ecossistemas, o que é, simultaneamente, fértil e frágil. Deve-se atentar ainda para o fato de que o conhecimento tradicional é protegido por dispositivos legais que ordenam a repartição dos benefícios decorrentes das descobertas científicas, incluindo o compartilhamento do lucro, com a comunidade de origem da informação (Brasil, 20 maio 2015). Benefícios que, segundo Albuquerque e Hanazaki (2006), correm o risco de se perder na estrutura burocrática ineficaz.

\section{A intermediação da bioética ambiental no uso de zooterápicos}

A decisão de como e quando utilizar animais como medicamentos é balizada por valores que variam de acordo com a posição e os interesses dos atores envolvidos. Isso gera um dilema possível de ser analisado e equacionado pela bioética ambiental. Para tanto, é fundamental o estabelecimento do diálogo entre os atores a fim de negociar os interesses culturais, econômicos e ambientais e alcançar valores éticos compartilhados e soluções consensuais e justas para todos. Inúmeros pesquisadores já têm registrado sugestões como: (a) criação de um banco nacional de remédios derivados de animais, o 
qual pode ser usado na conservação e manejo, além de documentar o conhecimento de comunidades cujas características culturais estão em risco; (b) desenvolvimento de pesquisa colaborativa e multidisciplinar; (c) preconização de medidas regulatórias, certificadoras e formulação de estratégias de monitoramento do comércio no tocante à procedência, armazenamento, exposição ao sol, umidade e condições de higiene; (d) regulamentação de quais animais podem ser criados e manejados e de como fazê-lo; (e) elaboração de projetos de sustentabilidade envolvendo análise de mercado com indicador (Guo et al., 1997; Alves, Rosa, 2005; Alves et al., 2007, 2008a, 2008b; Souto et al., 2011).

O problema de um modelo de gestão autoritário e arbitrário dos recursos naturais, tal como atestado por Fischer et al. (2016a) no caso dos recursos hídricos, é que ele prejudica as relações sociais ao conduzir uma prática social para a ilegalidade, gerando desconexões, conforme alertado por Alves et al. (2007). Costa-Neto (1999) ressaltou que, em vez de criminalizar os praticantes da zooterapia ou de forçá-los a abandonar o costume, a academia deveria observar a interação homem/animal sob a perspectiva cultural. Segundo o autor, não é a superação da prática que poupará a extinção da fauna. Se fosse assim, considerando os próprios mecanismos evolutivos, a prática não teria sido incorporada pela humanidade. Logo, parece óbvia a necessidade de um modelo de gestão participativa e de monitoramento cooperativo do uso de animais na medicina, capaz de congregar representantes de todos os segmentos sociais, inseridos no primeiro, segundo e terceiro setores de órgãos ambientais, da saúde, educação, comércio e líderes comunitários. Essa gestão deve ser intermediada por um profissional que domine a bioética como ferramenta deliberativa, provavelmente inserida em comitês multidisciplinares de bioética ambiental (Fischer et al., 2017), tal como sugerido na gestão do ecoturismo (Fischer et al., 2014) e da água (Fischer et al., 2016a). Alves et al. (2007) ressaltaram a necessidade de mudança de foco para assegurar o uso futuro dos animais como recurso e de múltiplos olhares que propiciem a avaliação global e interrelacionada de componentes ecológicos e sociais. Os comitês são essenciais na definição de metas, priorização de iniciativas e elaboração de planos de ação.

As decisões conjuntas são previstas pela Lei da Biodiversidade (Brasil, 20 maio 2015), que, em seu artigo 8, atribui ao Estado o reconhecimento do direito de populações indígenas e de comunidades de agricultores tradicionais participarem da tomada de decisões, no âmbito nacional, sobre assuntos relacionados à conservação e ao uso sustentável de seus conhecimentos tradicionais associados ao patrimônio genético do país. A lei também prevê o direito de propriedade intelectual, incluindo os royalties de produtos gerados a partir desse conhecimento. Segundo Alves e Rosa (2005), a adoção de medidas regulatórias pode permitir que o produto seja vendido sem aprovação oficial, embora deva atender a normas e critérios de segurança predeterminados, assim suplantando os desafios inerentes à implementação de medidas sanitárias com a participação de todos os envolvidos. Para Alves e Dias (2010), o comércio ilegal não declara, não regulamenta, não combate e não monitora. Para Alves e Rosa (2005), o respeito e a comunicação demandam investimento monetário, de tempo e de boas intenções. O conhecimento guardado pelas populações tradicionais pode representar recurso para inúmeros processos e produtos na agricultura, na medicina, no ramo de alimentos e de cosméticos. Costa-Neto (2011) considera fundamental o cuidado e a gestão da biodiversidade, gerando bases para debates sobre biologia da conservação, 
saúde pública, desenvolvimento sustentável, prospecção biológica e desenvolvimento de patentes. Em concordância com a proposta do presente estudo na constituição dos comitês de bioética ambiental, ressalta-se a inferência de Costa-Neto (2011) de que o governo, com seus órgãos ambientais e de saúde, deve garantir a coparticipação dos usuários no debate, que cabe se estender à obtenção, ao preparo e à administração dos zooterápicos, inseridos em um sistema popular de cura. Dessa forma, mesmo sendo uma questão de interesse global, a discussão e a implementação de ações devem estabelecer uma comunicação com a especificidade local.

\section{Considerações finais}

A Declaração universal sobre bioética e direitos humanos (Unesco, 2005) defende que os interesses e o bem-estar do indivíduo devem prevalecer sobre o interesse exclusivo da ciência ou da sociedade, destacando-se a importância da diversidade cultural e do pluralismo. Da mesma forma, a declaração impõe a promoção da saúde e do desenvolvimento social em benefício dos povos como objetivo fundamental dos governos, sem distinção de raça, religião, opções políticas e condição econômica ou social. Esse objetivo deve ser fomentado por meio do acesso aos cuidados de saúde, medicamentos, alimentação e água, assim viabilizando as condições de vida e otimizando a relação com o ambiente por meio da interação entre os seres humanos e as outras formas de vida. Ressalva-se igualmente a importância do acesso aos recursos biológicos e genéticos e ao uso adequado deles; o respeito pelos saberes tradicionais e o papel dos seres humanos na proteção da biosfera e da biodiversidade. É consenso que a saúde humana depende da biodiversidade e do funcionamento saudável dos ecossistemas. Da mesma forma, o manejo sustentável dos animais como recursos requer o entendimento dos aspectos socioculturais do uso da fauna no contexto da conservação. A literatura consultada no desenvolvimento do presente estudo atesta a amplitude e a abrangência temporal, cultural e geográfica da zooterapia, a qual não deve ser negligenciada por setores acadêmicos e regulatórios da sociedade. Logo, se faz urgente o estabelecimento de uma comunicação multidimensional e sem ruídos entre os agentes morais representantes dos três pilares da sustentabilidade - sociedade, ambiente e economia - envolvidos nessa questão ética global e complexa. Eles devem focar nas prioridades de conservação e produção sustentável, levando em conta valores naturais, culturais e econômicos.

\section{NOTA}

\footnotetext{
${ }^{1}$ A abordagem de comunidade moral adotada no presente estudo é fundamentada na reflexão filosófica de Felipe (2007). Segundo a autora, a comunidade moral é composta por componentes racionais e vulneráveis. Os primeiros são originários dos agentes morais, representando os setores da sociedade cujas decisões podem impactar negativamente setores que não têm poder de escolha, denominados pacientes morais. Diante de uma visão contratualista presume-se que a ética deve ser estabelecida entre dois agentes morais, contudo, a autora defende a inclusão na comunidade moral dos pacientes morais, tais como seres vivos não humanos, representados por animais e ecossistemas.
} 


\section{REFERÊNCIAS}

ADAMI, Eliana R.; CHEMIN Márcia R.C.; FRANÇA, Helena $S$.

Aspectos éticos e bioéticos da pesquisa clínica no Brasil. Estudos de Biologia: Ambiente e Diversidade, v.36, n.1, p.1-15. 2014.

ALBUQUERQUE, Ulysses P. de; HANAZAKI, Natália.

As pesquisas etnodirigidas na descoberta de novos fármacos de interesse médico e farmacêutico: fragilidades e perspectivas. Revista Brasileira de Farmacognosia, v.16, n.1, p.678-689. 2006.

ALMEIDA, Cecília de F.C.B.R.; ALBUQUERQUE, Ulysses P. de.

Uso e conservação de plantas e animais medicinais no estado de Pernambuco (Nordeste do Brasil): um estudo de caso. Interciência, v.27, n.6, p.276-285. 2002.

ALONSO-CASTRO, Angel Josabad et al. Zootherapeutic practices in Aquismón, San Luis Potosí, México. Journal of Ethnopharmacology, v.138, n.1, p.233-237. 2011.

ALVES, Rômulo R.N.

Relationships between fauna and people and the role of ethnozoology in animal conservation. Ethnobiology and Conservation, v.1, n.2, p.1-69. 2012.

ALVES, Rômulo R.N.; ALVES, Humberto N. The faunal drugstore: animal-based remedies used in traditional medicines in Latin America. Journal of Ethnobiology and Ethnomedicine, v.7, n.1, p.1-43. 2011.

ALVES, Rômulo R.N.; DIAS, Thelma L.P. Usos de invertebrados na medicina popular no Brasil e suas implicações para conservação. Tropical Conservation Science, v.3, n.2, p.159-174. 2010.

ALVES, Rômulo R.N.; ROSA, Ierecê L. From cnidarians to mammals: the use of animals as remedies in fishing communities in NE Brazil. Journal of Ethnopharmacology, v.107, n.2, p.259-276. 2006.

ALVES, Rômulo R.N.; ROSA, Ierecê L. Why study the use of animal products in traditional medicines? Journal of Ethnobiology and Ethnomedicine, v.1, p.1-5. 2005.

ALVES, Rômulo R.N.; SOUTO, Wedson M.S. Ethnozoology: a brief introduction. Ethnobiology and Conservation, v.4, n.1, p.1-13. 2015.

ALVES, Rômulo R.N.; SOUTO, Wedson M.S. Ethnozoology in Brazil: current status and perspectives. Journal of Ethnobiology and Ethnomedicine, v.7, n.1, p.1-5. 2011.
ALVES, Rômulo R.N. et al.

Traditional uses of medicinal animals in the semi-arid region of northeastern Brazil. Journal of Ethnobiology and Ethnomedicine, v.8, n.41, p.17. 2012.

ALVES, Rômulo R.N. et al.

Primates in traditional folk medicine: a world overview. Mammal Review, v.40, n.2, p.155-180. 2010a.

ALVES, Rômulo R.N. et al.

An ethnozoological survey of medicinal animals commercialized in the markets of Campina Grande, NE Brazil. Human Ecology Review, v.17, n.1, p.11-17. 2010b.

ALVES, Rômulo R.N. et al.

Commercialization of animal-derived remedies as complementary medicine in the semi-arid region of Northeastern Brazil. Journal of Ethnopharmacology, v.124, n.3, p.600-608. 2009.

ALVES, Rômulo R.N. et al.

Animal-based remedies as complementary medicines in Santa Cruz do Capibaribe, Brazil. BMC Complementary and Alternative Medicine, v.8, n.1, p.1-9. 2008a.

ALVES, Rômulo R.N. et al.

Reptiles used in traditional folk medicine: conservation implications. Biodiversity and Conservation, v.17, n.8, p.2037-2049. 2008b.

ALVES, Rômulo R.N. et al.

The role of animal-derived remedies as complementary medicine in Brazil. BioScience, v.57, n.11, p.949-955. 2007.

ANDRADE, Juliana N.; COSTA-NETO, Eraldo M. Primeiro registro da utilização medicinal de recursos pesqueiros na cidade de São Félix, Estado da Bahia, Brasil. Acta Scientiarum. Biological Sciences, v.27, n.2, p.177-183. 2005.

ANVISA.

Agência Nacional de Vigilância Sanitária.

Farmacopeia homeopática brasileira.

Disponível em: http://www.anvisa.gov.br/ farmacopeiabrasileira/conteudo/3a_edicao.pdf. Acesso em: 6 maio 2015. 2011.

ANVISA.

Agência Nacional de Vigilância Sanitária. Instrução normativa n.9. Dispõe sobre a relação de produtos permitidos para dispensação e comercialização em farmácias e drogarias. Disponível em: https://www. diariodasleis.com.br/busca/exibelink. php? numlink=212010. Acesso em: 2 ago. 2016. 17 ago. 2009. 
ANVISA.

Agência Nacional de Vigilância Sanitária. Resolução-RDC n.67. Dispõe sobre boas práticas de manipulação de preparações magistrais e oficinais para uso humano em farmácias. Disponível em: http://bvsms.saude.gov.br/bvs/ saudelegis/anvisa/2007/res0067_08_10_2007. html. Acesso em: 2 ago. 2016.8 out. 2007.

\section{ANVISA.}

Agência Nacional de Vigilância Sanitária. Resolução da Diretoria Colegiada (RDC) n.26. Dispõe sobre o registro de medicamentos dinamizados industrializados homeopáticos, antroposóficos e anti-homotóxicos. Disponível em: http://www.cff.org.br/userfiles/3\%20-\%20 AG\%C3\%8ANCIA\%20NACIONAL\%20DE\%20 VIGILANCIA\%20SANITARIA\%202007\%20 RDC\%2026\%20de\%202007.pdf. Acesso em: 2 ago. 2016. 30 mar. 2007.

ANYINAM, Charles.

Ecology and ethnomedicine: exploring links between current environmental crisis and indigenous medical practices. Social Science and Medicine, v.40, n.3, p.321-329. 1995.

BARBOSA, José A.A.; ALVES, Rômulo R.N. "Um chá de quê?" Animais utilizados no preparo tradicional de bebidas medicinais no agreste paraibano. BioFar: Revista de Biologia e Farmácia, v.4, n.2, p.1-12. 2010.

BARBOZA, Raynner et al.

The use of zootherapeutics in folk veterinary medicine in the district of Cubati, Paraíba State, Brazil. Journal of Ethnobiology and Ethnomedicine, v.3, n.1, p.1-32. 2007.

BARDIN, Laurence.

Análise de conteúdo. Lisboa: Edições 70/LDA. 1982.

BAUMAN, Zygmunt.

A ética é possível num mundo de consumidores? Rio de Janeiro: Zahar. 2011.

BENÍTEZ, Guillermo.

Animals used for medicinal and magicoreligious purposes in western Granada Province, Andalusia (Spain). Journal of Ethnopharmacology, v.137, n.3, p.1113-1123. 2011.

BETLU, Albert Lalduhawma Sajem.

Indigenous knowledge of zootherapeutic use among the Biate tribe of Dima Hasao District, Assam, Northeastern India. Journal of Ethnobiology and Ethnomedicine, v.9, n.1, p.1-16. 2013.

BEZERRA, Dandara Monalisa Mariz et al. Birds and people in semiarid northeastern Brazil: symbolic and medicinal relationships. Journal of Ethnobiology and Ethnomedicine, v.9, n.1, p.1-11. 2013.
BOFF, Leonardo.

Ética e ecoespiritualidade. Campinas: Verus. 2003.

BRASIL.

Lei n.13.123. Dispõe sobre o acesso ao patrimônio genético, sobre a proteção e o acesso ao conhecimento tradicional associado e sobre a repartição de benefícios para conservação e uso sustentável da biodiversidade. Disponível em:http://www.planalto.gov.br/ccivil_03/_ Ato2015-2018/2015/Lei/L13123.htm. Acesso em: 24 nov. 2017. 20 maio 2015.

BRASIL.

Lei n.10.683; decreto n.6.101; portaria n.44. Reconhecer como espécies da fauna brasileira ameaçadas de extinção aquelas constantes da Lista Nacional Oficial de Espécies da Fauna Ameaçadas de Extinção. Disponível em: http:// pesquisa.in.gov.br/imprensa/jsp/visualiza/index. jsp?jornal=1\&pagina $=121 \&$ data $=18 / 12 / 2014$. Acesso em: 24 nov. 2017. 17 dez. 2014.

BRASIL.

Lei n.11.794. Procedimentos para o uso científico de animais. Disponível em: http:// www.planalto.gov.br/ccivil_03/_ato20072010/2008/lei/111794.htm. Acesso em: 2 ago. 2016. 8 out. 2008 .

BRASIL.

Lei n.9.605. Dispõe sobre as sanções penais e administrativas derivadas de condutas e atividades lesivas ao meio ambiente, e dá outras providências. Disponível em: http://www. planalto.gov.br/ccivil_03/leis/L9605.htm. Acesso em: 24 nov. 2017. 12 fev. 1998.

CHAKRAVORTY, Jharna et al.

Vertebrates used for medicinal purposes by members of the Nyishi and Galo tribes in Arunachal Pradesh (North-East India). Journal of Ethnobiology and Ethnomedicine, v.7, n.1, p.1-14. 2011.

CHELLAPPANDIAN, Muthiah et al. Documentation and quantitative analysis of local ethnozoological knowledge among traditional healers of Theni district, Tamil Nadu, India. Journal of Ethnopharmacology, v.154, n.1, p.116-130. 2014.

\section{CONCEA.}

Conselho Nacional de Controle de Experimentação Animal. Normativas do Concea para produção, manutenção ou utilização de animais em atividades de ensino ou pesquisa científica. Disponível em: http://www.mct.gov. br/upd_blob/0238/238343.pdf. Acesso em: 2 ago. 2016. 2015.

COSTA-NETO, Eraldo M.

A zooterapia popular no estado da Bahia: registro de novas espécies animais utilizadas 
como recursos medicinais. Ciência e Saúde Coletiva, v.16, n.1, p.1639-1650. 2011.

COSTA-NETO, Eraldo M.

Recursos animais utilizados na medicina tradicional dos índios Pankararé que habitam no nordeste do estado da Bahia, Brasil. Actualidades Biológicas, v.21, n.1, p.69-79. 1999.

COSTA-NETO, Eraldo M.; MOTTA, Paulo C. Animal species traded as ethnomedicinal resources in the Federal District, Central West Region of Brazil. The Open Complementary Medicine Journal, v.2, n.1, p.22-39. 2010.

COSTA-NETO, Eraldo M.; OLIVEIRA, Maria V.M.

Cockroach is good for asthma: zootherapeutic practices in Northeastern Brazil. Human Ecology Review, v.7, n.2, p.41-51. 2000.

COSTA-NETO, Eraldo M.; PACHECO, Josué M. Utilização medicinal de insetos no povoado de Pedra Branca, Santa Terezinha, Bahia, Brasil. Biotemas, v.18, n.1, p.113-133. 2005.

COSTA-NETO, Eraldo M.; RESENDE, Janete Jane. A percepção de animais como 'insetos' e sua utilização como recursos medicinais na cidade de Feira de Santana, Estado da Bahia, Brasil. Acta Scientiarum. Biological Sciences, v.26, n.2, p.143149. 2008.

COSTA PINTO, Angélica A.; MADURO, Cice B. Produtos e subprodutos da medicina popular comercializados na cidade de Boa Vista, Roraima. Acta Amazônica, v.33, n.2, p.281-290. 2003.

CRF-PR.

Conselho Regional de Farmácia do Estado do Paraná. Código de ética farmacêutico. Disponível em: http://www.cff.org.br/sistemas/geral/ revista/pdf/76/08-codigodeetica.pdf. Acesso em: 2 ago. 2016. 2014.

FELIPE, Sônia T.

Agência e paciência moral: razão e

vulnerabilidade na constituição da comunidade moral.ethic@: An International Journal for Moral Philosophy, v.6, n.3, p.69-82. 2007.

FERREIRA, Felipe $S$. et al. Conservation of animals traded for medicinal purposes in Brazil: can products derived from plants or domestic animals replace products of wild animals? Regional Environmental Change, v.16, n.2, p.543-551. 2016.

FERREIRA, Felipe S. et al.

The trade of medicinal animals in Brazil: current status and perspectives. Biodiversity and Conservation, v.22, n.4, p.839-870. 2013.
FERREIRA, Felipe S. et al.

Animal-based folk remedies sold in public markets in Crato and Juazeiro do Norte, Ceará, Brazil. BMC Complementary and Alternative Medicine, v.9, n.1, p.1-8. 2009.

FIGUEIREDO, Napoleão.

Os 'bichos' que curam: os animais e a medicina de 'folk' em Belém do Pará. Boletim do Museu Paraense Emílio Goeldi. Ciências Humanas, v.10, n.1, p.75-91. 1994.

FISCHER, Marta L., OLIVEIRA, Gracinda M. Ética no uso de animais: a experiência do Comitê de Ética no Uso de Animais da Pontifícia Universidade Católica do Paraná. Estudos de Biologia, v.34, n.83, p.247-260. 2012.

FISCHER, Marta L. et al.

Da ética ambiental à bioética ambiental: antecedentes, trajetórias e perspectivas. História, Ciências, Saúde - Manguinhos, v.24, n.2, p.391409. 2017.

FISCHER, Marta L. et al.

Crise hídrica em publicações científicas: olhares da bioética ambiental. Revista Ambiente e Água, v.11, n.3, p.586-600. 2016a.

FISCHER, Marta L. et al.

Um olhar da bioética para a zooterapia. Revista Latinoamericana de Bioética, v.16, n.1, p.172-197. 2016b.

FISCHER, Marta L. et al.

Interfaces entre a bioética ambiental e o ecoturismo. Bioethikos, v.8, n.4, p.413-421. 2014.

FRANCIONE, Gary L.

Introdução aos direitos dos animais: seu filho ou cachorro. Campinas: Editora Unicamp. 2013.

GONZÁLEZ, José A. et al.

The use of wild vertebrates in contemporary Spanish ethnoveterinary medicine. Journal of Ethnopharmacology, v.191, p.135-151. 2016.

GUO, Yinfeng et al.

Sustainability of wildlife use in traditional Chinese medicine. Conserving China's Biodiversity, v.1-3, n.1, p.190-220. 1997.

HERNANDEZ, Jorge; CAMPOS, Claudia M.; BORGHI, Carlos E.

Medicinal use of wild fauna by mestizo communities living near San Guillermo Biosphere Reserve (San Juan, Argentina). Journal of Ethnobiology and Ethnomedicine, v.11, n.1, p.110. 2015.

HUFFMAN, Michael A.

Animal self-medication and ethno-medicine: exploration and exploitation of the medicinal properties of plants. Proceedings of the Nutrition Society, v.62, n.2, p.371-381. 2003. 
HUFFMAN, Michael A.

Current evidence for self-medication

in primates: a multidisciplinary

perspective. American Journal of Physical

Anthropology, v.104, n.25, p.171-200. 1997.

HUTCHINGS, Michael R. et al.

Can animals use foraging behaviour to combat parasites? Proceedings of the Nutrition Society, v.62, n.2, p.361-370. 2003.

KIM, Hyun; SONG, Mi-Jang.

Ethnozoological study of medicinal animals on Jeju Island, Korea. Journal of Ethnopharmacology, v.146, n.1, p.75-82. 2013.

LEV, Efraim.

Traditional healing with animals (zootherapy): medieval to present-day Levantine practice. Journal of Ethnopharmacology, v.85, n.1, p.107118. 2003.

LIMA, Jaciara R.B.; SANTOS, Carlos A.B. Recursos animais utilizados na medicina tradicional dos índios Pankararu no nordeste do Estado de Pernambuco, Brasil. Etnobiologia, v.8, n.1, p.39-50. 2010.

LIPTON, Bruce H.

A biologia da crença. São Paulo: Butterfly. 2007.

LIU, Changhua; GU, Man.

Protecting traditional knowledge of Chinese medicine: concepts and proposals. Frontiers of Medicine, v.5, n.2, p. 212-218. 2011.

LYRA-NEVES, Rachel M., et al.

Ethnozoology in Brazil: analysis of the methodological risks in published studies. Brazilian Journal of Biology, v.75, n.4, supl.1, p.184-191. 2015.

MARQUES, José G.W.

Fauna medicinal: recurso do ambiente ou ameaça à biodiversidade. Mutum, v.1, n.1, p.1-4. 1997.

MARTÍNEZ, Gustavo J.

Use of fauna in the traditional medicine of native Toba (qom) from the Argentine Gran Chaco region: an ethnozoological and conservationist approach. Ethnobiology and Conservation, v.2, n.2, p.1-43. 2013.

MORIN, Edgar.

A cabeça bem-feita: repensar a reforma, reformar o pensamento. Rio de Janeiro: Bertrand. 2003.

MOOTOOSAMY, Anushka; MAHOMOODALLY, M. Fawzi.

A quantitative ethnozoological assessment of traditionally used animal-based therapies in the tropical island of Mauritius. Journal of Ethnopharmacology, v.154, n.3, p.847-857. 2014.
MOURA, Flávia de B.P.; MARQUES, José G.W. Zooterapiapopular na Chapada Diamantina: uma medicina incidental? Ciência e Saúde Coletiva, v.13, n.2, p.2179-2188. 2008.

MS.

Ministério da Saúde. Política Nacional de Práticas Integrativas e Complementares. Disponível em: http://bvsms.saude.gov.br/bvs/publicacoes/ pnpic.pdf. Acesso em: 2 ago. 2016. 2006.

MS.

Ministério da Saúde. Política Nacional de Medicamentos. Disponível em: http://bvsms. saude.gov.br/bvs/publicacoes/politica medicamentos.pdf. 2001. Acesso em: 2 ago. 2016. 2001.

NASCIMENTO, André L.B. et al.

Functional aspects of the use of plants and animals in local medical systems and their implications for resilience. Journal of Ethnopharmacology, v.194, n.1, p.348-357. 2016.

QUIRINO, Glauberto da S.

Scientific and traditional knowledge: it is good for what? Ciência e Educação, v.21, n.2, p.273283. 2015.

REGAN, Tom.

Jaulas vazias: encarando o desafio dos direitos dos animais. Porto Alegre: Lugano. 2006.

SILVA, Andréa L. da

Animais medicinais: conhecimento e uso entre as populações ribeirinhas do rio Negro, Amazonas, Brasil. Boletim do Museu Paraense Emílio Goeldi. Ciências Humanas, v.3, n.3, p.343-357. 2008.

SILVA, Maria Letícia V. et al.

A zooterapia no Recife (Pernambuco): uma articulação entre as práticas e a história.

Biotemas, v.17, n.1, p.95-116. 2004.

SINGER, Peter.

Libertação animal. Porto Alegre: Lugano. 2004.

SONG, Mi-Jang; KIM, Hyun.

Analysis of ethnoveterinary treatments for cattle (Bos indicus) diseases referred in Sanrimgyeongje including twelve volumes of literature from the 7th to the 18th century. Journal of Ethnopharmacology, v.133, n.2, p.474-479. 2011.

SOUTO, Wedson M.S. et al.

Medicinal animals used in ethnoveterinary practices of the 'Cariri Paraibano', NE Brazil. Journal of Ethnobiology and Ethnomedicine, v.7, n.1, p.1-19. 2011.

STILL, Jessica.

Use of animal products in traditional Chinese medicine: environmental impact and health hazards. Complementary Therapies in Medicine, v.11, n.2, p.118-122. 2003. 
ULYSSÉA, Mônica A. et al.

Percepção e uso dos insetos pelos moradores da comunidade do Ribeirão da Ilha, Santa Catarina, Brasil. Biotemas, v.23, n.3, p.191-202. 2010.

\section{UNESCO.}

Organização das Nações Unidas para a Educação, a Ciência e a Cultura. Declaração Universal sobre Bioética e Direitos Humanos. Disponível em: http://unesdoc.unesco.org/ images/0014/001461/146180por.pdf. Acesso em: 2 ago. 2016. 2005.

VALLEJO, José Ramón; GONZÁLEZ, José Antonio. Fish-based remedies in Spanish ethnomedicine: a review from a historical perspective. Journal of Ethnobiology and Ethnomedicine, v.10, n.1, p.1-31. 2014.
VATS, Rajeev; THOMAS, Simion. A study on use of animals as traditional medicine by Sukuma Tribe of Busega District in North-western Tanzania. Journal of Ethnobiology and Ethnomedicine, v.11, n.1, p.1-11. 2015.

VÁZQUEZ, Patricia Enríquez et al.

Uso medicinal de la fauna silvestre en los Altos de Chiapas, México. Interciencia, v.31, n.7, p.491499. 2006.

VIJAYAKUMAR, S. et al.

Ethnozoological study of animals used by traditional healers in Silent Valley of Kerala, India. Journal of Ethnopharmacology, v.162, n.1, p.296-305. 2015.

\section{$\rightarrow \rightarrow \rightarrow<<<$}

